\title{
Trampoline injury in New Zealand: emergency care.
}

\author{
Patria A Hume, David J Chalmers, Barry D Wilson
}

School of Physical Education, University of Otago, Dunedin, New Zealand

P A Hume, overseas fellow B D Wilson, senior lecturer

\section{Injury Prevention}

Research Unit, Department of Preventive and Social Medicine, University of Otago, Dunedin, New Zealand D J Chalmers, deputy director

Correspondence to: Dr David J Chalmers, Injury Prevention Research Unit, Department of Preventive and Social Medecine, Medical School, University of Otago, PO Box 913 Dunedin, New Zealand.

Accepted for publication 5 June 1996

\begin{abstract}
Objective-To examine trampoline related injuries resulting in emergency department attendance.

Methods-Cases were identified by searching free text descriptions of the circumstances of injury contained in the records of the emergency department of a large city hospital.

Results-114 cases were identified for a 12 month period, giving an incidence rate of 108 per 100000 population per year (95\% confidence interval $=89$ to 129 ) compared with 9.3 hospital admissions per 100000 population per year ( $95 \%$ confidence interval $=8.3$ to 10.4 ) for a corresponding period reported in earlier research from New Zealand. This suggested that for every one hospital admission there are approximately 12 emergency department attendances. Of the cases, $95 \%$ were aged less than 20 years. As for the earlier research, falls from the trampoline to the surrounding surface were the commonest cause of injury. In the present study, sprains and strains were the commonest type of injury $(40 \%)$, and the body site most frequently involved was the lower limb (46\%).

Conclusions-The findings support the conclusion from earlier research that although existing trampoline standards address many of the issues relating to trampoline safety, the need remains for measures to reduce the impact of falls from the trampoline to the ground surface and to prohibit the use of trampolines as unsupervised "play equipment".

(Br F Sports Med 1996;30:327-330)
\end{abstract}

Key terms: trampoline; recreation; injury; epidemiology

In an earlier paper we reviewed the shifting fortunes of the trampoline and reported the results of a study which had examined deaths and hospital admissions associated with this equipment over a 10 year period in New Zealand. ${ }^{1}$ During that period, two deaths and 2098 hospital admissions had occurred. Both deaths involved children with disabilities, in residential care, and unsupervised at the time of the incident; both are believed to have struck the frame of the trampoline. The majority of injuries resulting in hospital admission occurred on home trampolines (71\%), most involved falls from the trampoline to the ground surface $(80 \%)$, fractures were the most common injury (68\%), and the body site most frequently injured was the upper limb (53\%). No evidence was found of a high incidence of serious head and neck injuries, the cause of concern in some countries. ${ }^{2-4}$ This was in spite of an apparently high exposure to trampolines in New Zealand, where they are commonly used for recreational purposes, compared to countries such as Denmark where the predominant use was in physical education or gymnastics. On the basis of these findings we were unable to support previous calls for the banning of trampolines. ${ }^{2-7}$ In accepting the potential dangers associated with this equipment and its increasing popularity for recreational use, we recommended the strengthening of existing standards $^{89}$ to require impact absorbing materials on surrounding surfaces and the prohibition of trampolines as unsupervised "play equipment" in any setting. ${ }^{1}$

While the above study described the incidence, nature, and circumstances of the more serious outcomes of trampoline related injury in New Zealand, we were aware that deaths and hospital admissions represent only part of any injury problem. The purpose of the present study, therefore, was to supplement the above information by examining trampoline related injuries resulting in emergency department attendances. Whereas most previous research has concentrated on case studies of catastrophic injury, three studies have attempted to provide a broader epidemiological perspective. Hammer et al described 195 cases presenting at the casualty department of a single hospital serving a population of 250000 on the outskirts of Copenhagen, Denmark, over the three years 1976-1978. ${ }^{2}$ Woodward et al described 114 cases presenting at the emergency department of a paediatric medical centre in Salt Lake City, Utah, USA, over an 18 month period from June 1989 to November $1990 .^{7}$ Finally, Routley described 452 injuries to children under 15 years of age presenting at the emergency departments of three hospitals in Victoria, Australia, over the period 1989 to 1991. ${ }^{10}$ In none of these studies were incidence rates reported, although Hammer et al ${ }^{2}$ provided sufficient information for rates to be estimated.

\section{Methods}

The source of data was the Dunedin Hospital emergency service injury data base for the 12 month period May 1989 to April 1990 inclusive. At the time of the study, Dunedin Hospital provided the only comprehensive emergency service for the city of Dunedin, which at that time had a population of approxi- 
mately 106000 people. All attendances at the emergency service for the treatment of injuries are recorded on the database and each attendance record contains a brief free text description of the circumstances of injury ( 80 characters). Cases were identified by means of a computer search of this free text field for occurrences of the key word "tramp" and those clearly identified as involving a trampoline were retained. Cases requiring follow up treatment are entered as separate records in the database. To avoid the double counting of cases, such reattendances were excluded from the analyses.

Nature of injury is coded on the database according to a coding frame modelled on that developed for the Australian National Injury Surveillance and Prevention Project. ${ }^{11}$ Cases are not coded for severity of injury. The circumstances of injury were first coded according to the World Health Organisation's International classification of diseases (ICD) ${ }^{12}$ (Supplementary classification of external causes of injury and poisoning [E codes]). They were also classified according to a coding frame developed for the purpose of the project, which included the following categories: fell off the trampoline and struck the ground surface or an external object; fell onto the bed of the trampoline; collided with another person on the trampoline; struck against the frame of the trampoline; struck by the frame of the trampoline (for example, when unfolding trampoline); other; and unspecified. There was insufficient information on the database to distinguish between mini and full size trampolines or between gymnastic and recreational trampolines. Neither was there sufficient information to identify the place of occurrence.

The population of the catchment area served by Dunedin Hospital was obtained from the 1986 population census. ${ }^{13}$ Confidence intervals were calculated following the method described by Snedecor and Cochrane. ${ }^{14}$ All analyses were conducted using the SAS system for personal computers. ${ }^{15}$

\section{Results \\ One hundred and fourteen first attendances were identified for the study period. These accounted for $0.5 \%$ of attendances at the Dun- edin Hospital emergency service. Of the 114 cases in Dunedin, 60 were male (53\%) and 54 $(47 \%)$ were female. One hundred and eight victims $(95 \%)$ were aged less than 20 years. The table shows the incidence rates by age groups, with the 10-14 year age group having the highest rate of 510 per 100000 persons per year $(95 \%$ confidence interval $=374$ to 681$)$.}

Incidence rates for attendances at the Dunedin Hospital emergency service by age group, May 1989-April 1990

\begin{tabular}{lcccl}
\hline Age group (years) & Frequency & Population & Rate* & 95\% Confidence interval \\
\hline $0-4$ & 15 & 7374 & 203 & 113 to 336 \\
$5-9$ & 37 & 7548 & 490 & 345 to 676 \\
$10-14$ & 46 & 9012 & 510 & 374 to 681 \\
$15-19$ & 10 & 12051 & 83 & 40 to 153 \\
$20+$ & 6 & 69897 & 9 & 3 to 19 \\
Total & 114 & 105882 & 108 & 89 to 129
\end{tabular}

^ Rate per 100000 persons per year.
The rate for those under 20 years of age was 300 per 100000 persons per year $(\mathrm{CI}=246$ to 362 ), compared with the incidence rate for all ages of 108 per 100000 persons per year $(\mathrm{CI}=$ 89 to 129). By extrapolation, we estimate that there were 3500 attendances at emergency departments for the whole of New Zealand for trampoline related injuries during the study period. The most common category of injury was sprains and strains (40\%), followed by fractures $(22 \%)$, cuts and lacerations $(17 \%)$, contusions $(10 \%)$, and other categories of injury (3\%). In 10 cases $(9 \%)$, no diagnosis was recorded. In only one case was a second injury reported and this involved a sprain/ strain. The most frequently injured body region was the lower limb (46\%), followed by the head and neck $(22 \%)$, and upper limb $(17 \%)$. Other regions accounted for $9 \%$ of cases and the body region could not be classified for those 10 cases for which no diagnosis was recorded. Of the 52 injuries to the lower limb, 15 were to the ankle; of the 25 to the head and neck, 15 were to the face, cheek, forehead, or skull (excluding vault); and of the 17 to the upper limb, nine were to the radius/ulna. The majority of patients were treated and discharged (62\%), with $18 \%$ being treated and referred to a fracture clinic, $7 \%$ treated and referred to a general practitioner, and $2 \%$ treated and referred to another service. Three cases were admitted to hospital (3\%). The discharge history for 10 cases was unknown.

According to the $\mathrm{ICD}^{12}$ classification of external causes of injury (E codes), 38 of the incidents (33\%) involved falls "from one level to another" (E884), 12 (11\%) involved collisions (E917), and $64(56 \%)$ were classified as "unspecified" (E928) as there was insufficient information available to provide a more precise classification. When the events were categorised according to the coding frame developed for the project, it was found that of the 38 who fell, 32 fell off the trampoline and struck the ground surface or an external object, and six fell onto the bed of the trampoline. Of the 12 collisions, seven involved striking the frame of the trampoline, four involved being struck by the trampoline (for example, when unfolding the trampoline), and one involved a collision with another person.

A three way cross tabulation by cause of injury, nature of injury, and body region indicated that for the 29 incidents in which the victim fell off the trampoline and struck the ground surface, the most common injuries were a sprain or strain to the lower limb $(n=8)$ or a fracture of the upper limb $(n=8)$.

\section{Discussion}

As for hospital admissions, ${ }^{1}$ the great majority of emergency department attendances involved people under the age of 20 years $(95 \%)$. This was also found to be the case in the study by Hammer $\mathrm{et} \mathrm{al}^{2}$ in which $74 \%$ of victims were aged 6-19 years. The studies reported by Woodward $e t a l^{7}$ and Routley ${ }^{10}$ were limited to child populations.

Whereas the highest rate reported for hospital admissions was for the 5-9 year age group 
(30 per 100000 persons per year), ${ }^{1}$ the highest rate in the present study was for the 10-14 year age group at 510 per 100000 persons per year. No other studies reported rates, but from the figures reported by Hammer et $a l^{2}$ it was possible to determine that the incidence rate for those aged 6-19 years was 88 per 100000 persons per year (confidence interval $=74$ to 103 ). In the present study the incidence rate for those aged 5-19 years was almost four times this, at 325 per 100000 persons per year (confidence interval $=262$ to 398 ). While this contrast may be due to time differences between the two studies (Hammer et $a l^{2}$ reported their study in 1981), it would appear that trampolining in Copenhagen took place mostly as an organised activity in schools and clubs, while in New Zealand the trampoline is more likely to be found in recreational use in residential settings. ${ }^{1}$ This finding supports our earlier contention that trampolines should not be used as "play equipment" in any setting, including the home. ${ }^{1}$ It would appear that this message is pertinent to the USA and Australia as well. In their American study, Woodward et $a l^{7}$ reported that $48 \%$ of their patients were injured using their family's trampoline and $51 \%$ were injured on trampolines belonging to friends, neighbours, or relatives. In their Australian study, Routley ${ }^{10}$ reported that $76 \%$ of injuries occurred in backyards.

There appears to be no consistency between studies with regard to the sex of victims. In the present study there were more male than female victims, at a ratio of $1.1: 1$. A similar ratio was reported by Woodward et al ${ }^{7}$ (1.2:1) but both Hammer et $a l^{2}$ and Routley ${ }^{10}$ reported higher female to male ratios, at 1.6:1 and 1.2:1 respectively. We found also that for hospital admissions the female rate at 21.9 per 100000 persons per year was higher than that for males at 13.9 per 100000 persons per year. ${ }^{1}$

Whereas for hospital admissions we found that fractures were the most common injury $(68 \%)$, followed by intracranial injury $(12 \%)$, sprains $(6 \%)$, and dislocations $(6 \%),{ }^{1}$ in the present study we found that the most common category of injury was sprains and strains $(40 \%)$, followed by fractures $(22 \%)$, cuts and lacerations $(17 \%)$, and contusions $(10 \%)$. The two studies also differed with regard to the site of injury. For hospital admissions, the most common site of injury was the upper limb $(53 \%)$, followed by the lower limb $(22 \%)$, head $(16 \%)$, and trunk ( $7 \%) .{ }^{1}$ In contrast, we found in the present study that the most common body region was the lower limb (46\%), followed by the head and neck $(22 \%)$ and upper limb $(17 \%)$. It is difficult to draw comparisons with the studies by Hammer et $a l,{ }^{2}$ Woodward et $a l^{7}$ and Routley, ${ }^{10}$ due to variations in the methods of classification used in each. These three studies differed from ours also, in that a higher percentage of victims appeared to have suffered more serious injuries; whereas in the present study three cases were admitted to hospital, $23 \%$ of those reported by Woodward et $a l^{7}$ and $15 \%$ of those reported by Routley ${ }^{10}$ were admitted to hospital, and Hammer et $a l^{2}$ reported that $40 \%$ of their cases required more than one day of treatment.

In our earlier study of hospital admissions, we found that $80 \%$ of incidents involved a fall from the trampoline to the surrounding surface, followed by falling onto the bed of the trampoline $(8 \%)$, and striking the frame of the trampoline $(2 \%) .{ }^{1}$ In the present study, detailed information on the circumstances of injury was available for only 50 cases but of these, $64 \%$ involved falling from the trampoline to the surrounding surface, $14 \%$ striking the frame of the trampoline, $12 \%$ falling onto the bed of the trampoline, $8 \%$ being struck by the trampoline, and $2 \%$ involving collisions with other people on the trampoline. Again, it is difficult to draw comparisons with the studies by Hammer et $a l,{ }^{2}$ Woodward et $a l,{ }^{7}$ and Routley ${ }^{10}$ due to variations in the methods of classification used. Nevertheless, the above three causes rank high among those reported in these studies.

The findings of this study have shown that deaths and hospital admissions are indeed only the tip of the iceberg with regard to injury associated with trampolines. Using data from our two studies, it would appear that for every one hospital admission there are approximately 12 emergency department attendances. Even this provides an underestimate of the problem, since we have no measure of presentations to general practices or other health services.

While there are variations between our two studies in the ranking of nature, site, and cause of injury, it is evident that the limbs and the head and neck are vulnerable to injury and that the commonest injuries are fractures, sprains, and strains. It is also evident that the three leading causes of injury are falls onto the surrounding surface (be it the ground or obstacles in close proximity to the trampoline), impacts with the trampoline frame, and falls onto the bed of the trampoline. The findings reported by Hammer et al, ${ }^{2}$ Woodward et al, ${ }^{7}$ and Routley ${ }^{10}$ are consistent with this conclusion. Finally, no evidence has been found in this or the previous study ${ }^{1}$ of a high incidence of severe head and neck injuries of the kind that have led to calls for the banning of trampolines in several countries. ${ }^{2-7}$

On the basis of the above, we reaffirm our earlier conclusion that there is insufficient evidence to support the notion of a total ban on the use of the trampoline in this country. ${ }^{1}$ We also reaffirm our earlier recommendations and support $^{1}$ for the New Zealand trampoline standard NZS 5855:1993 ${ }^{\circ}$ which adopts and improves upon ASTM F381-84. ${ }^{8}$ Finally, we reaffirm our earlier call for further consideration to be given to measures that will reduce the impact of falls from trampolines and to prohibiting the use of trampolines as unsupervised "play equipment" in any setting, including the home."

This project was funded by a grant from the Accident Rehabilitation and Compensation Insurance Corporation (ACC) of New Zealand. The Injury Prevention Research Unit is funded jointly by the ACC and the Health Research Council of New Zealand. We are grateful to Dunedin Hospital for the provision of Emergency Service data; to the School of Physical Education University of Otago, for the use of computer facilities; to 
Stephen Marshall, Biostatistician with the Injury Prevention Research Unit, for his assistance with the statistical analyses; and to Dr Anne Isaac, Trampoline Coach, for her comments on earlier versions of this paper. The opinions expressed in this paper are not necessarily those of the above organisations and individuals.

1 Chalmers DJ, Hume PA, Wilson BD. Trampolines in New Zealand: a decade of injuries. $\mathrm{Br} \mathfrak{f}$ Sports Med 1994;28:234-8.

2 Hammer A, Schwartzbach AL, Paulev PE. Trampoline training injuries: one hundred and ninety-five cases. $\mathrm{Br} \mathcal{F}$ Sports Med 1981;15:151-8.

3 Rapp GF, Nicely PG. Trampoline injuries. Am $\mathcal{f}$ Sports Med 1978;6:269-71.

4 Torg JS, Das M. Trampoline-related quadriplegia: review of literature and reflections on the American Academy of Pediatrics' position statement. Pediatrics 1984;74:804-12.

5 American Academy of Pediatrics. Committee on Accident and Poison Prevention: policy statement: Trampolines. Evanston,

6 Hammer A, Schwartzbach AL, Paulev PE. Some risk factors in trampolining illustrated by six serious injuries. $\mathrm{Br} f$ Sports Med 1982;16:27-32.
7 Woodward GA, Furnival R, Schunk JE. Trampolines revisited: a review of 114 pediatric recreational trampoline revisited: a review of 114 pediatric
injuries. Pediatrics 1993;89:849-54.

8 American Society for Testing and Materials. Standard consumer safety specification for components, assembly, and use of a trampoline (ASTM F381-84). Philadelphia: American Society for Testing and Materials, 1984.

9 Standards Association of New Zealand. New Zealand Standard: Consumer safety specification for components, assembly, and use of a trampoline (NZS 5855:1993). Wellington: Standards Association of New Zealand, 1993.

10 Routley V. Trampoline injuries Hazard 1992;13:1-5.

11 Hartley P. NISPP coding manual, 3rd ed. Adelaide: National Injuries Surveillance and Prevention Project, 1988.

12 World Health Organisation. International classification of diseases, 1975 revision. Geneva: WHO, 1977

13 Department of Statistics. New Zealand Census of Population and Dwellings. Usually-Resident Population, Series B, Report 25. Wellington: Department of Statistics, 1987.

14 Snedecor GW, Cochrane WG. Statistical methods, 7th ed. Ames: The Iowa State University Press, 1980.

15 SAS Institute. SAS language guide for personal computers, release 6.03 edition. Cary, NC: SAS Institute Inc, 1988.

\section{BASM Merchandise 1996}

Ladies scarves White with blue border and BASM logo - $\quad £ 5+£ 1$ p\&p 27-inch square

Navy blue with fringe and BASM logo

$£ 5+£ 1 \mathrm{p} \& \mathrm{p}$

$54 \times 9$ inches (oblong)

Ties $\quad$ Single motif

Multi motif

Blazer badge Wire -4 inches high

$£ 6+£ 1 \mathrm{p} \& \mathrm{p}$

$£ 6+£ 1 \mathrm{p} \& \mathrm{p}$

Wire -3 inches high

$£ 5+£ 1 \mathrm{p} \& \mathrm{p}$

$£ 5+£ 1 \mathrm{p} \& \mathrm{p}$

\section{New stock to order}

Sweaters Lambswool fine knit, V-neck or round neck with small motif. Machine washable.

$£ 32+£ 1 \mathrm{p} \& \mathrm{p}$

State colour and chest size required.

Slipovers Lambswool fine knit, V-neck, with small

$£ 30+£ 1 \mathrm{p} \& \mathrm{p}$ motif. Machine washable. State colour and chest size required.

Sweatshirts With small motif.

State colour and chest size required.

Polo shirts

With small motif.

$£ 18+£ 1 \mathrm{p} \& \mathrm{p}$

State colour and chest size required.

Send orders to John H Clegg JP BSc LDS RCS Eng, Hon Secretary, Birch Lea, 67 Springfield Lane, Eccleston, St Helens, Merseyside WA10 5HB, UK. (Tel: 01744 28198) 